\title{
Dietary Supplementation of Mushroom Water Suppresses Fat Accumulation in High Fat Diet Induced-Obese Female Mice and Enhances Immune Cell Development in Non-Obese Mice
}

\author{
So Jin Bing $\cdot$ Manh Tin Ho $\cdot$ Phorl Sophors $\cdot$ Sanggyu Park $\cdot$ Young Min Yun \\ - Youngheun Jee $\cdot$ Moonjae Cho*
}

Received: 22 December 2014 / Accepted: 14 January 2015 / Published Online: 31 March 2015

(C) The Korean Society for Applied Biological Chemistry 2015

\begin{abstract}
Extracted mushroom water showed an ability to suppress the accumulation of body fat in female mice after feeding 5 weeks with high fat diet. Particularly, in parametrial and mesenteric adipose, it significantly reduced 44 and $47 \%$ of weight, respectively. In non-obese mice, maturated NK cell $\left(\mathrm{CD} 11 \mathrm{~b}^{\text {hi }} \mathrm{CD} 27^{\mathrm{lo}}\right)$ population were increased $(70.9 \pm 3.8 \%)$ in mushroom water fed mice compared to control $(61.4 \pm 4.3 \%)$ and NK cell population were augmented in mushroom fed mice compared to control.
\end{abstract}

Keywords fat accumulation $\cdot$ high fat diet $\cdot$ immune-stimulator $\cdot$ mushroom $\cdot$ natural killer cell $\cdot$ obesity

Obesity plays major role as a contributor to some disease such as fatty liver disease, type 2 diabetes and cardiovascular diseases

S. J. Bing $\cdot$ Y. M. Yun $\cdot$ Y. Jee

Department of Veterinary Medicine and Veterinary Medical Research Institute, Jeju National University, Jeju 690-756, Republic of Korea

M.T. Ho · P. Sophors

Department of Biochemistry School of Medicine, Jeju National University, Jeju 690-756, Republic of Korea

S. Park

Division of Life \& Environmental Science, Daegu University, Daegu, 712714, Republic of Korea

\section{Cho}

Department of Biochemistry, School of Medicine, Institute of Medical Science, Jeju National University, Jeju 690-756, Republic of Korea

*Corresponding author (M. Cho: moonjcho@jejunu.ac.kr)

This is an Open Access article distributed under the terms of the Creative Commons Attribution Non-Commercial License (http://creativecommons. org/licenses/by-nc/3.0/) which permits unrestricted non-commercial use, distribution, and reproduction in any medium, provided the original work is properly cited.
(Zimmet et al., 2001; Kotronen and Yki-Jarvinen, 2008; van Dis et al., 2009). High fat diet (HFD) is one of main factors that contribute to the development of obesity (Buettner et al., 2007; Lee, 2013). Mushroom is an important natural source of medicine and healthy food with high nutrition, low-calorie, high quality proteins, vitamins and minerals (El Enshasy et al., 2013). Dietary supplementation with Shiitake mushrooms in a high-fat diet can prevent body weight gain, fat deposition, and plasma TAG (triacylglycerol) in rats (Handayani et al., 2011).

In general, the ability of medicinal mushrooms as immunestimulator is occurred via innate immunity that typically mediated by phagocytic cells. Phagocytic cells interact with pathogen components or ingest invading them that in either case further serve as stimulator for innate and adaptive immunity through cytokines and chemokine secretion (Hetland et al., 2008). Here we investigated the effects of mushroom water in high fat dietinduced obese mice and immune cell modulation in non-obese mice.

Mushroom water is effective to suppress fat accumulation in obese female mice. Total 16 male and female C5BL/67 mice, 68 weeks of ages, were divided into three groups; Group 1 or control: mice were fed with normal water and low fat diet $(18 \%$ calories from fat), Group 2 or HFD: mice were fed with normal water and high fat diet ( $45 \%$ calories from fat). Group 3 or HFDMR: Mice were fed with mushroom water and high fat diet. Mushroom water was produced from submerged Lentinus edodes mycelia and fruit body with Sawdust media by mixing $100 \mathrm{~g}$ (Saw dust media) with $1 \mathrm{~L}$ of distilled water and the extraction was carried out for 14 days at $25^{\circ} \mathrm{C}$. The residue was removed by centrifugation and the filtration. Mice have free access to water and food. The average amount intake per day of water and food is calculated everyday by measuring the left water in bottles and food weights, respectively. The mushroom concentration is 0.588 $\mathrm{mg} / \mathrm{mL}$ (as $10 \mathrm{mg}$ in $17 \mathrm{~mL} / \mathrm{mouse} /$ day).

After feeding 5 weeks, final body weight of male mice but not 
female, was significantly increased in HFD and HFD-MR group more than those in control group (Fig. 1A). This finding is similar with the result of cholesterol serum from plasma analysis (Fig. 1B).

In rat model for high fat diet-induced obesity, supplementation with Shiitake mushrooms is effective to prevent alterations of plasma lipid profiles, fat deposition, energy efficiency, and body fat index [7]. To define the effect of mushroom water on high fat diet-induced fat accumulation in mice, we examined the visceral (mesenteric, parametrial, and retroperitoneal) and subcutaneous fat by measuring some fat pads from mesenteric, parametrial, retroperitoneal, and subcutaneous adipose tissues. After feeding 5 weeks, mice were sacrificed for getting fat pads. There is no significant change of fat accumulation of male mice among three groups although body weight was significantly higher in HFD and HFD-MR than control group (Fig. 1A and data not shown). Interestingly, in female mice, although body weight was not different between control and HFD-fed group, the weight of all white adipose tissue was significantly higher in the HFD group than control. However, our result showed that total fat mass in male was still higher than female mice although there is a significant different among male group (data not shown). Mushroom feeding could rescue high fat diet-induced body fat deposition in female mice by suppressing the accumulation of visceral adipose tissue, particularly in parametrial and mesenteric adipose with significantly lowered 44 and $47 \%$ of weight respectively, compared the HFD group (Fig. 1C). The previous study showed that dietary supplementation with fungal chitosan extracted from white mushroom exoskeleton (Agaricus bisporus) could prevent obesity in high fat diet-induced obese mice by decreasing feed efficiency, fat mass, adipocytokine secretion and ectopic fat deposition in the liver and the muscle (Neyrinck et al., 2009). However, our results indicated the mushroom supplementation was only effective to suppress fat accumulation in female mice, no change on body weight gain, and had no effect on both body weight and fat accumulation in male mice. Taken together, our results indicated that mushroom water supplementation showed an ability to suppress the high fat diet-induced accumulation of visceral fat in female but not in male mice.

Historically, this loss-weight gain effect of mushroom diet has been reported recently. Chronic mushroom intake was indicated to reduce the weight gain and blood glucose level in male and female after 12 weeks (LaMacchia et al., 2014). Interestingly, in 2014, Harry Marsales et al. (2014) have reported the similar effect with our present study that mushroom intake could separately influence on glucose and insulin levels in male and female, this indicated that mushroom could specific effect on female on regulating the balance required to level-out blood sugar levels and keep the body at a healthy weight (Marsales et al., 2014).

Mushroom water enhanced the immune cells development. Mice was divided into male and female groups $(n=6)$, fed low fat diet ( $18 \%$ calories from fat) with or without mushroom water. After 5 weeks, mice were sacrificed to collect spleen to isolate immune cells for analysis.
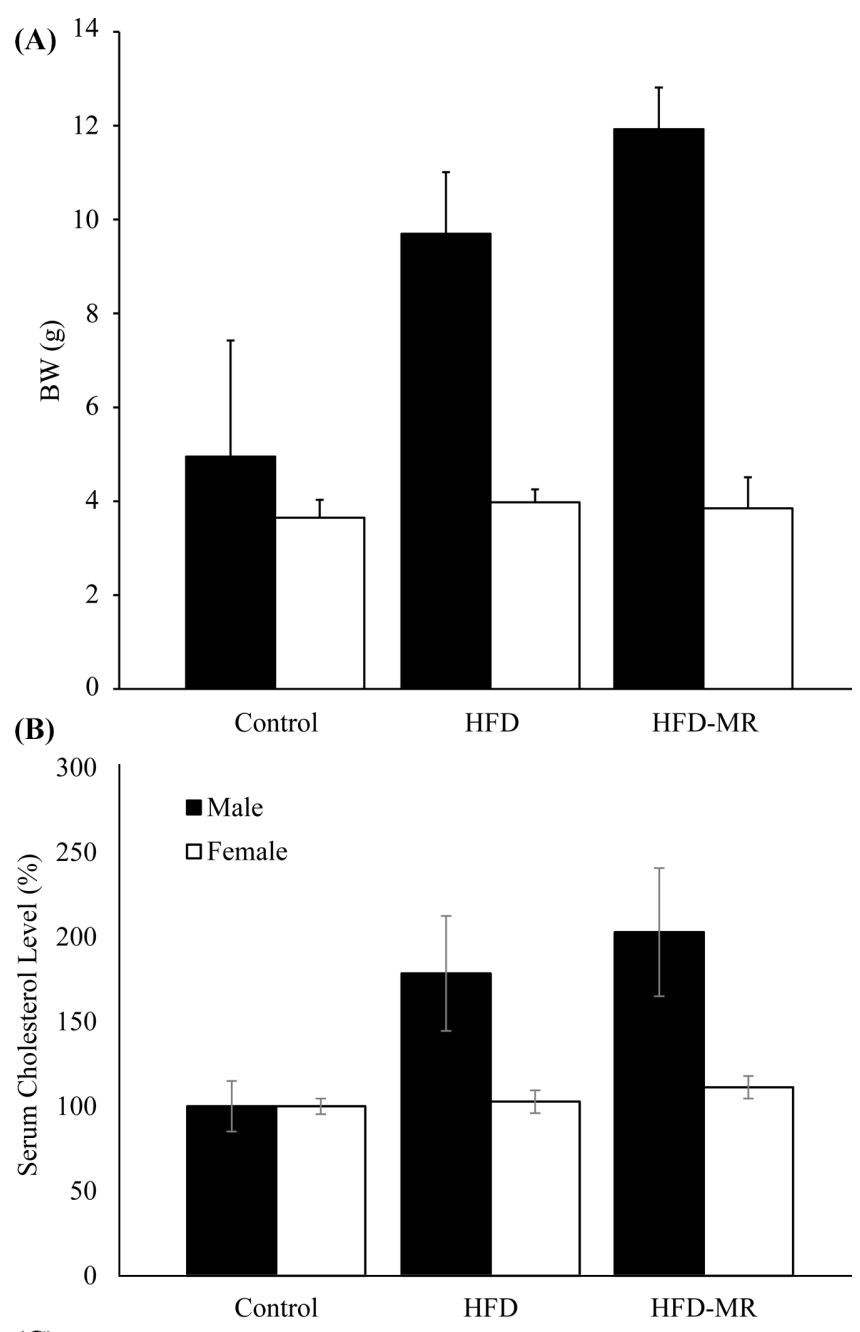

(C)

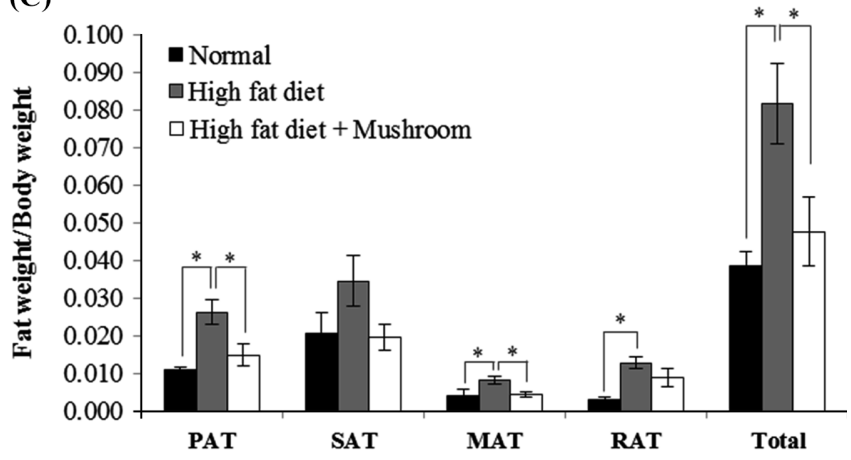

Fig. 1 Mushroom water intake is effective to suppress high fat dietinduced body fat accumulation in female mice. Mice were fed with mushroom water and foot, the intake amount has evaluated every day. The average amount of water and foot is about $17 \mathrm{ml} /$ day and $4 \mathrm{~g}$, respectively. After 5 weeks, the mice were sacrified to collect fat tissue. (A and B) Total gained weights and cholesterol serum in plasma after feeding 5 weeks. (C) Dietary intake of mushroom water suppresses the accumulation of visceral fat, such as mesenteric, parametrial, and retroperitoneal adipose tissue. Data are mean \pm SEM and asterisks represent statistical differences between groups; ${ }^{*} p<0.05,{ }^{* *} p<0.005$. BW; Body Weight, HFD; High Fat Diet, HFD-MR; High Fat Diet with Mushroom Water, PAT; Parametrial Adipose Tissue, SAT; Subcutaneous Adipose Tissue, MAT; Mesenteric Adipose Tissue, RAT; Retroperitoneal Adipose Tissue. 
(A)

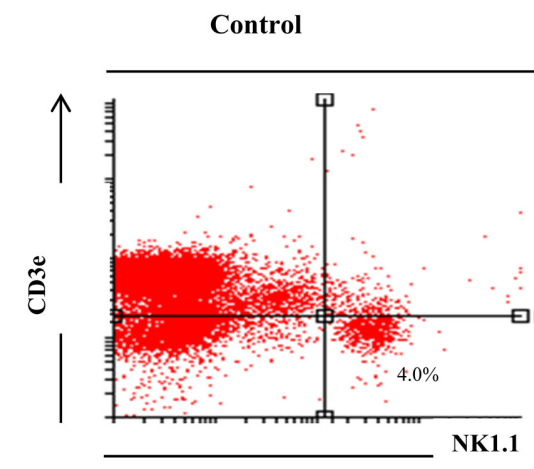

Mushroom
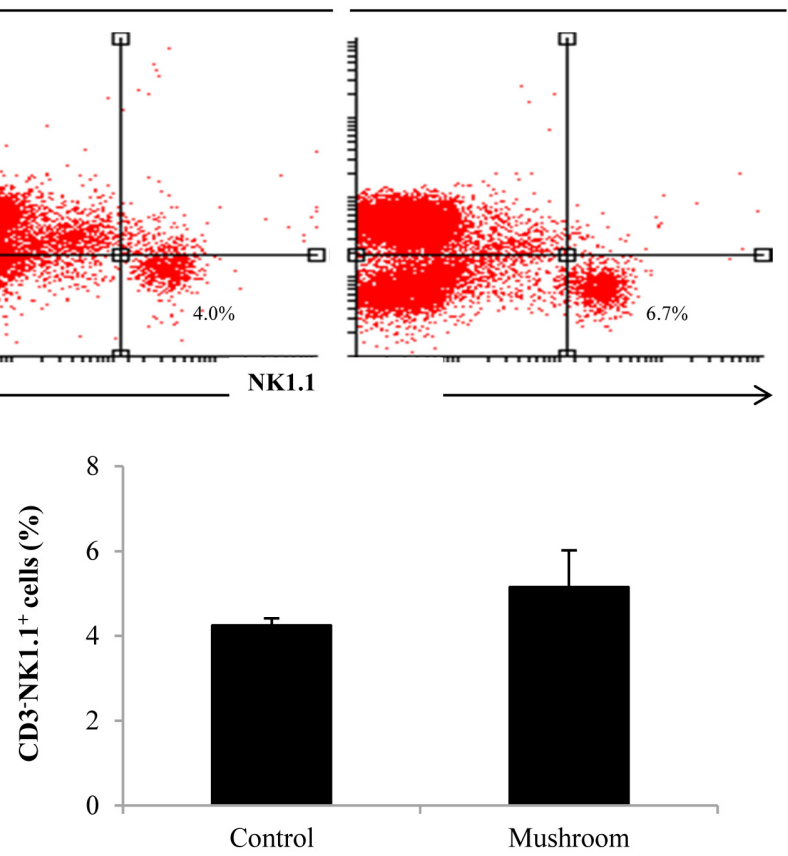

(B)
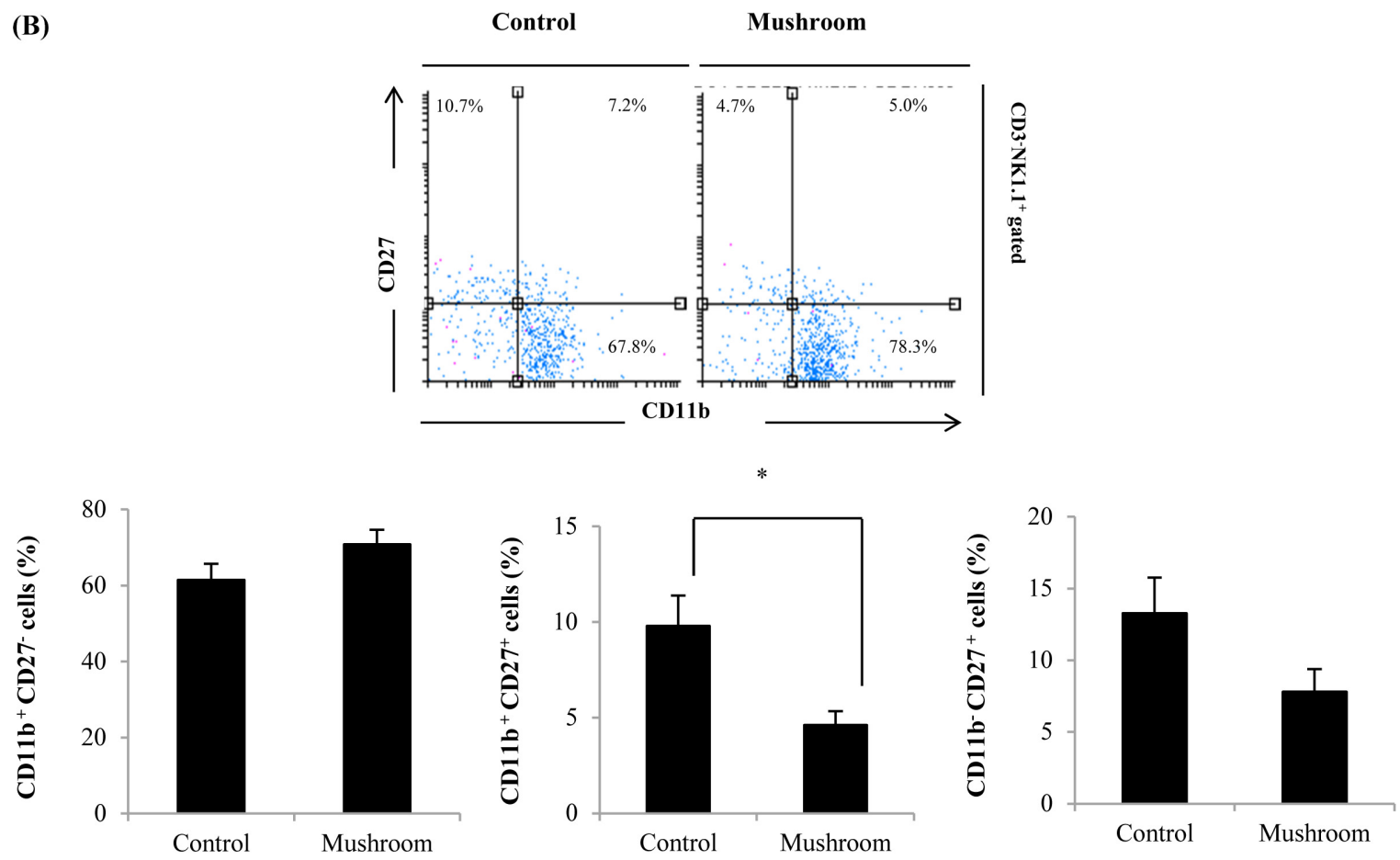

Fig. 2 NK cell maturation was affected by mushroom treatment and showed proportionally greater frequency of innate immune cell than control, particularly conventional DCs (cDC). Isolated splenic mononuclear cells from control and mushroom-treated mice were analyzed for immune cell population. (A) The percentage of NK cells $\left(\mathrm{CD} 3 \mathrm{e}^{-} \mathrm{NK} 1.1^{+}\right)$was higher in mushroom-treated mice than in controls. (B) Representative flow-cytometric dot plots of CD11b and CD27 expression on gated NK cells $\left(\mathrm{CD} 3 \mathrm{e}^{-} \mathrm{NK} 1.1^{+}\right)$from spleen. Numbers in quadrants represent percentages of total NK cells in corresponding quadrants. NK cells from mushroom-treated mice were highly enriched for differentiated NK subsets $\left(\mathrm{CD} 11 \mathrm{~b}^{\text {high }} \mathrm{CD} 27^{\text {low }}\right)$. Conversely, the proportion of immature NK cells $\left(\mathrm{CD} 11 \mathrm{~b}^{\text {low }} \mathrm{CD} 27^{\text {high }}\right)$ was decreased in mushroom-treated mice. (C). Representative flow-cytometric dot plots of $\mathrm{CD} 11 \mathrm{~b}$ and $\mathrm{CD} 11 \mathrm{c}$ expression on gated lymphocytes $\left(\mathrm{CD} 45^{+}\right)$from spleen. Bars in histograms represent mean \pm SEM Bars in histograms represent mean \pm SEM. The nonparametric Mann-Whitney test was used to calculate P values between control and mushroom-treated groups. 
(C)
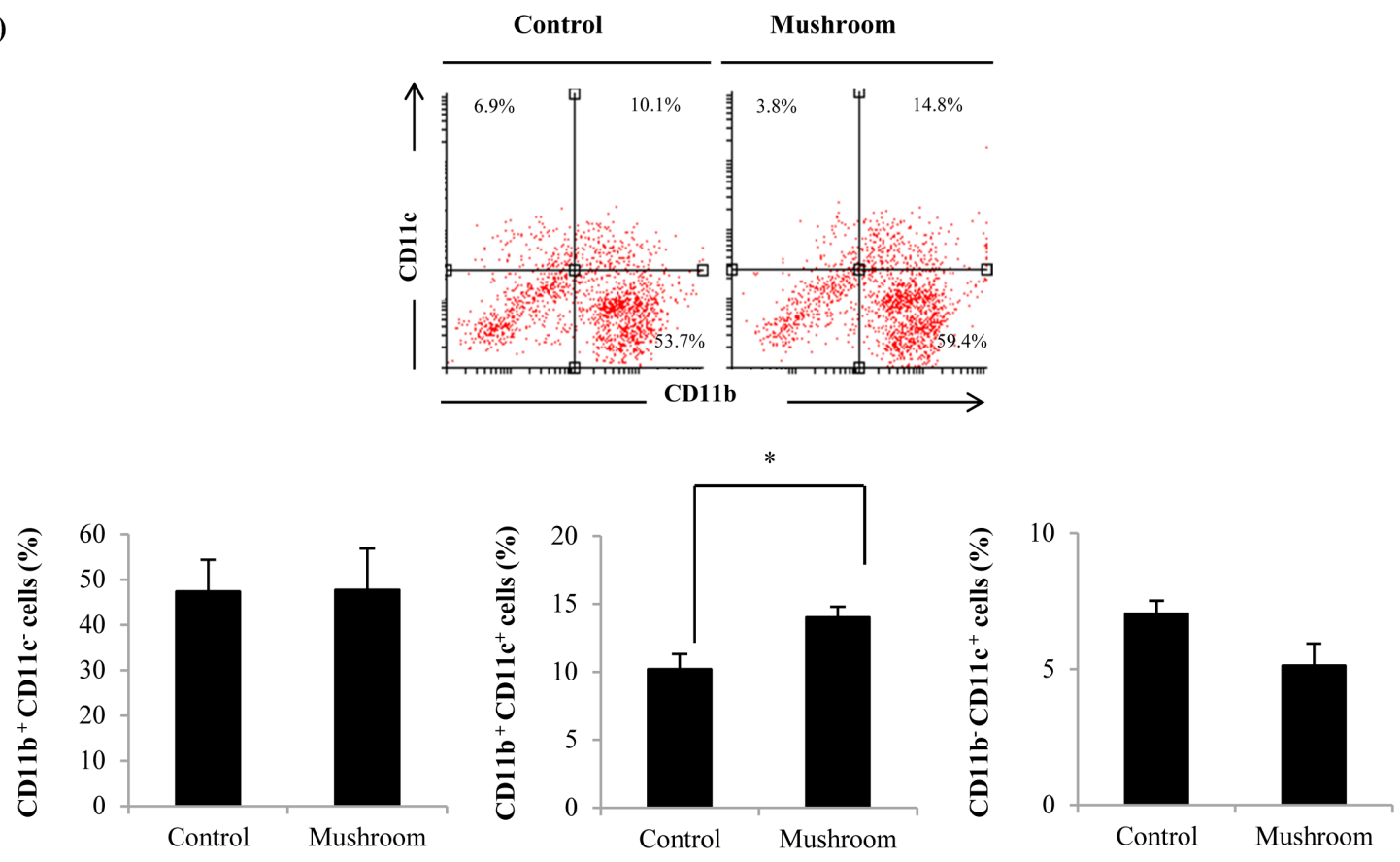

Fig. 2 Continued

The mushroom extract was also reported that they have immune system induction like increasing the natural killer cells activity, inducing dendritic cell differentiation, etc (Ahn et al., 2004; Torkelson et al., 2012). Thus, to define whether mushroom affects the cell population in splenic mononuclear cells, we quantified the number of various cells $\left(\mathrm{CD} 4^{+}, \mathrm{CD} 8^{+} \mathrm{T}\right.$ cells, $\mathrm{B}$ cell, NK cells, macrophage, and dendrite cells) in spleen with flow cytometry. Single cells in suspensions of spleen (contained $1 \times 10^{6}$ cells) were stained with antibodies directly labeled with one of following fluorescent tags; CD3 (145-2c11), CD4 (H129.19), CD8 (53-6.7), CD45 (Ly-5), CD11b (M1/70), CD27 (LG.3A10), NK1.1 (PK136) (BD Biosciences, USA) and CD11c (HL3) (eBioscience, USA). Appropriate isotype controls (mouse IgG, Sigma, USA) were always included. Twenty thousand viable cells per mouse (as determined by light scatter profiles) were analyzed by using BD FACS CaliburTM flow cytometer (BD Biosciences). The cell surface expression of CD27 and CD11b is used to designate the maturation stage of NK cells. There are 4-stage model of NK-cell maturation $\mathrm{CD} 11 b^{\text {low }} \mathrm{CD} 27^{\text {low }}, \mathrm{CD} 11 b^{\text {low }} \mathrm{CD} 27^{\text {high }}$, $\mathrm{CD} 11 b^{\text {high }} \mathrm{CD} 27^{\text {high }}$, CD11 ${ }^{\text {high }} \mathrm{CD} 27^{\text {low }}[13]$.

We demonstrated that the maturated NK cell $\left(\mathrm{CD} 11 \mathrm{~b}^{\text {hi }} \mathrm{CD} 27^{\mathrm{lo}}\right)$ population expanded to $70.9 \pm 3.8 \%$ compared to control group (Fig. 2B, 61.4 $\pm 4.3 \%$ ) along with increased NK cell population (Fig. 2A) in the mushroom-treated mice. The population of other cells ( $\mathrm{CD} 4^{+}, \mathrm{CD}^{+} \mathrm{T}$ cells, B cell, and macrophage) showed no difference (data not shown). In addition to NK cell expansion, conventional DCs $\left(\mathrm{cDC}, \mathrm{CD} 11 \mathrm{~b}^{+} \mathrm{CD} 11 \mathrm{c}^{+}\right)$, one of the innate cells, also expanded to $14.0 \pm 0.8 \%$ upon mushroom treatment compared to control group (Fig. 2C, 10.2 $\pm 1.1 \%$ ). This effect was also reported in the study of Ahn et al. (2004) about mushroom extract,
Agaricus blazei Murill Kyowa which showed the NK cells activity induction when treated on cancer patient undergoing chemotherapy (Ahn et al., 2004). Alternatively, Chaga mushroom extract demonstrated a capability of increasing cytokine expression and T-cell, B-cell proliferation (Kim, 2005). These findings suggested that the mushroom water has ameliorated the natural killer cell proliferation and indicated a potential ability in immune-stimulation in non-obese mice.

In conclusion, the mushroom water has been proven as a natural candidate in anti-obese and enhancing the immune system. Especially, it has specific effect on high fat diet female mice which reduced body fat accumulation without changing the body weight. This effect would develop for an anti-obese cosmetic therapy and potential functional food for immune system support.

Acknowledgment This research was supported by the 2014 scientific promotion program funded by Jeju National University.

\section{References}

Ahn WS, Kim DJ, Chae GT, Lee JM, Bae SM, Sin JI et al. (2004) Natural killer cell activity and quality of life were improved by consumption of a mushroom extract, Agaricus blazei Murill Kyowa, in gynecological cancer patients undergoing chemotherapy. Int J Gynecol Cancer 14, 589-94.

Buettner R, Scholmerich J, and Bollheimer LC (2007) High-fat diets: modeling the metabolic disorders of human obesity in rodents. Obesity (Silver Spring) 15, 798-808.

El Enshasy H, Elsayed EA, Aziz R, and Wadaan MA (2013) Mushrooms and truffles: historical biofactories for complementary medicine in Africa and in the middle East. Evid Based Complement Alternat Med 2013, 620451.

Handayani D, Chen J, Meyer BJ, and Huang XF (2011) Dietary Shiitake 
Mushroom (Lentinus edodes) Prevents Fat Deposition and Lowers Triglyceride in Rats Fed a High-Fat Diet. J Obes 2011, 258051.

Hetland G, Johnson E, Lyberg T, Bernardshaw S, Tryggestad AM, and Grinde B (2008) Effects of the medicinal mushroom Agaricus blazei Murill on immunity, infection and cancer. Scand J Immunol 68, 363-70.

Kim YR (2005) Immunomodulatory Activity of the Water Extract from Medicinal Mushroom Inonotus obliquus. Mycobiology 33, 158-62.

Kotronen A and Yki-Jarvinen H (2008) Fatty liver: a novel component of the metabolic syndrome. Arterioscler Thromb Vasc Biol 28, 27-38.

Lee CY (2013) The Effect of High-Fat Diet-Induced Pathophysiological Changes in the Gut on Obesity: What Should be the Ideal Treatment? Clin Transl Gastroenterol 4, e39.

Marsales H, Williams BT, LaMacchia ZM, Rideout TC, and Horvath PJ (2014) The effect of mushroom intake on modulating post-prandial glycemic response. The FASEB Journal 28, 647-8.
Neyrinck AM, Bindels LB, De Backer F, Pachikian BD, Cani PD, and Delzenne NM (2009) Dietary supplementation with chitosan derived from mushrooms changes adipocytokine profile in diet-induced obese mice, a phenomenon linked to its lipid-lowering action. Int Immunopharmacol 9, 767-73.

Torkelson CJ, Sweet E, Martzen MR, Sasagawa M, Wenner CA, Gay J et al. (2012) Phase 1 Clinical Trial of Trametes versicolor in Women with Breast Cancer. ISRN Oncol 2012, 251632.

van Dis I, Kromhout D, Geleijnse JM, Boer JM, and Verschuren WM (2009) Body mass index and waist circumference predict both 10-year nonfatal and fatal cardiovascular disease risk: study conducted in 20,000 Dutch men and women aged 20-65 years. Eur J Cardiovasc Prev Rehabil 16, $729-34$.

Zimmet P, Alberti KG, and Shaw J (2001) Global and societal implications of the diabetes epidemic. Nature 414, 782-7. 